\title{
Sperm DNA Damage In Smokers
}

\section{Original Article}

\section{Elsayed S. Hewedy ${ }^{1}$, Ghada F. Hassan', Rana M. Abo El Enein ${ }^{1}$, Mohammad A. Saad $^{2}$}

${ }^{1}$ Departments of Dermatology and Venereology and ${ }^{2}$ Clinical Pathology, Faculty of Medicine, Tanta University, Tanta, Egypt

\begin{abstract}
Background: Cigarette smoking is the largest preventable risk factor for morbidity and mortality in developed countries. It negatively affects male reproduction and fertility. Sperm DNA damage is one of the possible incriminating causes of diminishing fertility potential in smokers as there was a strong evidence of a link between oxidative DNA damage and the chronic complications of smoking. This has potential implications for their reproductive health, particularly given the association between sperm DNA damage and infertility, miscarriage in pregnancies fathered by these men, childhood disease.

Aim: The aim of this work was to assess the integrity of sperm DNA in infertile smoker patients.

Patients and methods: Sperm DNA damage was assessed using flow-cytometry in 30 infertile smoker male patients and 1 5-age matched healthy non-smoker fertile males as a control group.

Results: There was an increase in the DNA fragmentation index (DFI) in smokers when compared with controls. There was a significant positive correlation between DFI with the age of patients, smoking index and duration of smoking. A significant positive correlation between DFI and sperm morphology (abnormal forms \%) was found. On the other hand, there was a negative correlation between the DFI and other seminal parameters including semen volume (ml), sperm count (millions/ml) and sperm motility (active progressive $\%$, first hour).

Conclusion: This study suggested that smoking can cause sperm DNA damage that affects the quality of the ejaculated spermatozoa and their fertility potential and pregnancy outcome.
\end{abstract}

Keywords: DNA damage, male infertility, smokers.

Received: 28 May 2017, Accepted: 28 August 2017

Corresponding Author: Ghada Fawzy Rezk Hassan, Tel.: 0020402385213,E-mail: ghadafawzy53@yahoo.com

ISSN: 2090-6048, June 2017, Vol. 7, No. 2

\section{INTRODUCTION}

Over the past two decades, there has been increasing evidence that several environmental toxicants may impair semen quality and thus male fertility in animals as well as in human. Even exposure to episodic seasonal air pollution can have deleterious effects on human sperms ${ }^{[1]}$. Among different air pollutant, cigarette smoke contains toxic chemicals, mutagenic and carcinogenic compounds, which can adversely affect male fertility too ${ }^{[2]}$.

Cigarette smoke contains more than 4000 different chemical compounds, such as nicotine, nitrosamine, polycyclic aromatic, hydrocarbons, cadmium and carbon monoxide. Some of these substances were found in seminal plasma at concentrations proportional to those in the serum, suggesting their crossing of the blood-testis barrier. Thus, the seminal plasma of smokers can be considered as toxic environment for spermatozoa ${ }^{[3]}$.
Several studies showed a correlation between the consumption of tobacco and alternation of semen quality ${ }^{[4]}$. Conventional sperm parameters such as sperm density, motility, viability, morphology and nuclear integrity seem to be concerned ${ }^{[5]}$. Moreover smoking can be linked to significantly increased levels of seminal reactive oxygen species (ROS). This is why cigarette smoke may induce oxidative alteration in plasma membrane asymmetry and DNA damage in spermatozoa of healthy smokers ${ }^{[6]}$. It was concluded that smoking is associated with increased sperm DNA damage that may impair the reproductive capability of smokers ${ }^{[7]}$.

Sperm chromatin/DNA integrity is essential for the accurate transmission of paternal genetic information and normal chromatin structure is important for sperm fertilizing ability. The assessment of sperm DNA quality becomes essential with the increased use of assisted reproductive techniques as IVF and ICSI. Sperm DNA damage may be 
caused by exposure to gonadotoxins, diabetes mellitus , radiation, chemotherapy protamine deficiency, high level of ROS, abnormal apoptosis and varicocele ${ }^{[8]}$.

Small DNA damages in sperm are repaired by preand post-replication repair mechanisms, but large DNA damages cannot be repaired. Infertile men may have sperm with normal morphology, but with damaged $\mathrm{DNA}^{[9]}$. This results in pregnancy loss or birth of off springs with major or minor congenital malformations, severe dysmormphogenesis or may lead to increased predisposition to certain cancer like retinoblastoma. Thus, DNA integrity studies are very important in evaluation of infertile males ${ }^{[10]}$.

Aim: So the aim of this study was to assess the integrity of sperm DNA in infertile, smoker patients.

\section{PATIENTS AND METHODS}

The study was approved by the research ethics committee of the Faculty of Medicine, Tanta University (approval code 30334 /05/ 15), Tanta, Egypt on May/2015. This study was carried out on 30 infertile smoker male patients. They were collected from the Outpatient Clinic of the Dermatology and Venereology Department, Tanta University Hospital. The study included also a control group consisting of 15 age-matched, healthy, fertile, nonsmoker males. The study was explained for both patients and controls. All participants provided signed informed consent before being included in the study.

Patients were asked about the duration of smoking and the number of cigarette per day to calculate smoking index which is defined as the product of number of cigarettes/ day $\times$ years of smoking; (mild $<200$ SI, moderate 200-400 SI and heavy $>400 \mathrm{SI}$ ) (11), and the fertility history was also taken. Patients with other causes of sperm DNA damage as diabetes mellitus, leucocytospermia, varicocele, chemotherapy and radiotherapy will be excluded from the study. The controls and patients were subjected to history taking including history of previous treatment. None of the studied patients received any treatment for infertility at the time of the study or during the preceding 6 months. All men were also subjected to genital examination and colour Doppler ultrasound of the spermatic cord to exclude varicocele especially subclinical type.

\section{Laboratory investigations}

(1) Routine investigations such as urine analysis, complete blood picture, fasting and postprandial blood sugar, liver function tests and renal function tests (urea and creatinine).

(2) Sperm collection and semen analysis: all samples were collected by masturbation into polypropylene containers after 3-5 days of sexual abstinence. After liquefaction at $371 \mathrm{C}$, conventional semen analysis was carried out according to the guidelines of $\mathrm{WHO}^{[12]}$.

(3) The sperm chromatin structure assay (SCSA) was carried out using the BD FACS Calibur flow cytometer (Becton Dickinson, San Jose, California, USA) ${ }^{[13]}$. SCSA measures the susceptibility of sperm chromatin to DNA denaturation in situ after low-pH treatment, which potentially induces this DNA denaturation. This assay is an adaptation of the 'two-step acridine orange' (AO) procedure for simultaneous measurements of DNA and RNA content in somatic cells. By this procedure, protamineassociated DNA in sperm is denatured but somatic cell DNA associated with histones is not readily denatured. Red and green fluorescence from 5000 individual sperms per sample is collected through red (630 $\mathrm{nm}$ long-pass) and green (515-530 $\mathrm{nm}$ bandpass) filters.

An aliquot of the semen sample was diluted to $1-2 \times 106$ sperms $/ \mathrm{ml}$ using $1 \times$ TNE buffer $(0.01 \mathrm{~mol} / 1$ Tris-Cl, 0.15 $\mathrm{mol} / \mathrm{l} \mathrm{NaCl}, 1 \mathrm{mmol} / \mathrm{l}$ EDTA, diluted 1: 10 in $\mathrm{H}_{2} \mathrm{O}, \mathrm{pH}$ 7.4). Thereafter, a $200-\mu \mathrm{l}$ aliquot of the diluted sperm suspension was dispensed in a sampling tube suitable for use in a flow cytometer and $400 \mathrm{ml}$ acid detergent solution $(20 \mathrm{ml}$ of $2.0 \mathrm{~N} \mathrm{HCl}, 4.39 \mathrm{~g} \mathrm{NaCl}, 0.5 \mathrm{ml}$ Triton $\mathrm{X}-100, \mathrm{H} 2 \mathrm{O}$ to 500 $\mathrm{ml}, \mathrm{pH}$ adjusted to 1.2 with $5 \mathrm{~N} \mathrm{HCl}$ ) was added to it and gently mixed by swirling in the hand for $30 \mathrm{~s}$. Then $1.2 \mathrm{ml}$ AO staining solution ( $600 \mu \mathrm{l}$ AO stock solution per $100 \mathrm{ml}$ of staining buffer) was added; AO stains double-stranded (intact) DNA with green fluorescence and single-stranded (damaged) DNA with red fluorescence. The stained sample was placed into the flow cytometer to start sample flow immediately. At $3 \mathrm{~min}$, data acquisition was started by collecting green and red fluorescence from 5000 cells/ sample in list mode. The DNA fragmentation index \% (DFI \%) was calculated as the ratio between the red fluorescence and the total (red + green) fluorescence.

\section{Statistical analysis:}

Data were fed to the computer and analyzed using IBM SPSS software package version 20.0 (v 16; SPSS Inc., Chicago, IL, USA). Qualitative data were described using number and precent. Quantitative data were described using range (minimum and maximum), mean, standard deviation and median. Significance of the obtained results was judged at the $5 \%$ level.

\section{RESULTS}

This study included 30 infertile, smoker, male patients and 15 controls (non-smokers). The age of the patients ranged from $24-40$ years with a mean value of $30.93 \pm$ 4.43 years. The age of the control group ranged from 25 38 years with a mean value of $31.87 \pm 4.85$ years with no significant difference between both groups. 
Twenty six $(87 \%)$ of the studied patients complained of primary infertility, while only $4(13 \%)$ patients complained of secondary infertility, their wives were suffering from recurrent abortion. In this study $6(20 \%)$ patients were mild smokers, $15(50 \%)$ were moderate smokers and $9(30 \%)$ were heavy smokers according to SI. The duration of smoking in this study ranged from 5 - 20 years with a mean value of $9.30 \pm 3.34$ years.

According to guidelines of WHO (14), 24 (80\%) of patients showed asthenozoospermia. Although semen volume in the patient group was within normal, it was significantly lower than the control group. There was no statistically significant difference in mean value of sperm count in patients compared to the controls. There was statistically significant decrease in sperm motility in patients compared to control. On the other hand, there was a statistically significant increase in the sperm abnormal forms in patients compared to controls (Table 1).

There was a statistically significant negative correlation between SI and semen volume $(\mathrm{ml})$, sperm count (millions $/ \mathrm{ml}$ ) and motility (active progressive $\%$, first hour). On the other hand there was a positive correlation between SI and sperm morphology (abnormal forms) as shown in (Table 2). So heavy smokers have a lowest semen volume, sperm count and motility with increasing the abnormal forms in contrast to mild and moderate smokers and the controls.

The duration of smoking also affects semen parameters. A statistically significant negative correlation between the duration of smoking and semen volume, sperm counts and motility was found. While there was a statistically significant positive correlation between the duration of smoking and sperm morphology (abnormal forms) (Table 2).

Concerning the DNA fragmentation index (DFI), the patients showed a statistically significant increase when compared to the controls. In the patients, the DFI ranged from $25-38 \%$ with a mean value of $31.24 \pm 4.74$ while in the controls, it ranged from $410 \%$ - with mean value of $5.65 \pm 1.57$ ( $p$-value $<0.001 *$ ) as illustrated in figures $(1,2,3)$. There was a significant positive correlation between DFI and age of patients, smoking index (SI) and duration of smoking (Table 3). Table (3) also showed the correlations between DFI and seminal parameters in smokers. A significant positive correlation was found between DFI and sperm morphology (abnormal forms $\%$ ). While significant negative correlations could be detected between the DFI and other seminal parameters including: semen volume (ml), sperm count (millions/ $\mathrm{ml}$ ) and sperm motility (active progressive $\%$, first hour).

Table 1: Comparison between the studied groups according to semen analysis.

\begin{tabular}{|c|c|c|c|c|}
\hline Semen Analysis & $\begin{array}{l}\text { Patients } \\
(\mathrm{n}=30)\end{array}$ & $\begin{array}{l}\text { Controls } \\
(\mathrm{n}=15)\end{array}$ & $\mathrm{T}$ & $\mathrm{p}$ \\
\hline $\begin{array}{l}\text { Volume }(\mathrm{ml}) \\
\text { Min. - Max. } \\
\text { Mean } \pm \text { SD. } \\
\text { Median }\end{array}$ & $\begin{array}{l}2.0-5.0 \\
3.85 \pm 0.94 \\
4.0\end{array}$ & $\begin{array}{l}3.50-5.50 \\
4.53 \pm 0.64 \\
4.50\end{array}$ & $2.532 *$ & $0.015^{*}$ \\
\hline $\begin{array}{l}\text { Count }(\text { million } / \mathrm{ml}) \\
\text { Min. }- \text { Max. } \\
\text { Mean } \pm \text { SD. } \\
\text { Median }\end{array}$ & $\begin{array}{l}25.0-75.0 \\
55.93 \pm 17.98 \\
64.50\end{array}$ & $\begin{array}{l}40.0-75.0 \\
63.07 \pm 10.61 \\
65.0\end{array}$ & 1.668 & 0.103 \\
\hline $\begin{array}{l}\text { Motility (active } \\
\text { progressive \% first hour) } \\
\text { Min. }- \text { Max. } \\
\text { Mean } \pm \text { SD. } \\
\text { Median }\end{array}$ & $\begin{array}{l}20.0-40.0 \\
29.77 \pm 5.95 \\
29.0\end{array}$ & $\begin{array}{l}50.0-65.0 \\
57.73 \pm 5.96 \\
59.0\end{array}$ & 14.864* & $<0.001^{*}$ \\
\hline $\begin{array}{l}\text { Morphology } \quad \text { (abnormal } \\
\text { forms \%) } \\
\text { Min. - Max. } \\
\text { Mean } \pm \text { SD. } \\
\text { Median }\end{array}$ & $\begin{array}{l}18.0-28.0 \\
23.57 \pm 2.87 \\
24.0\end{array}$ & $\begin{array}{l}14.0-20.0 \\
16.80 \pm 1.93 \\
17.0\end{array}$ & $8.215^{*}$ & $<0.001 *$ \\
\hline
\end{tabular}

$\mathrm{t}, \mathrm{p}: \mathrm{t}$ and $p$ values for student $\mathrm{t}$-test

*: Statistically significant at $p \leq 0.05$ 
Table 2: Correlations between smoking index, duration of smoking and semen parameters in patients.

\begin{tabular}{|c|c|c|c|c|}
\hline & \multicolumn{2}{|c|}{ Smoking index } & \multicolumn{2}{|c|}{ Duration of smoking } \\
\hline & $\mathrm{r}$ & $\mathrm{P}$ & $\mathrm{R}$ & $\mathrm{P}$ \\
\hline Volume (ml) & $-0.908^{*}$ & $<0.001^{*}$ & $-0.770 *$ & $<0.001^{*}$ \\
\hline Count (million /ml) & $-0.932^{*}$ & $<0.001 *$ & $-0.747 *$ & $<0.001^{*}$ \\
\hline $\begin{array}{l}\text { Motility (active } \\
\text { progressive } \% \text { first hour) }\end{array}$ & $-0.759^{*}$ & $<0.001 *$ & $-0.742 *$ & $<0.001 *$ \\
\hline $\begin{array}{l}\text { Morphology } \\
\text { (abnormal forms \%) }\end{array}$ & $0.886^{*}$ & $<0.001^{*}$ & $0.793 *$ & $<0.001^{*}$ \\
\hline
\end{tabular}

r: Pearson coefficient

*: Statistically significant at $p \leq 0.05$

Table 3: Correlations between DFI and age, smoking index, duration of smoking, semen parameters in patients.

\begin{tabular}{|c|c|c|}
\hline \multicolumn{3}{|c|}{ DFI } \\
\hline & $\mathrm{r}$ & $\mathrm{P}$ \\
\hline Age & $0.689 *$ & $<0.001^{*}$ \\
\hline Smoking index & $0.927^{*}$ & $<0.001 *$ \\
\hline Duration of smoking & $0.766^{*}$ & $<0.001^{*}$ \\
\hline Volume (ml) & $-0.963 *$ & $<0.001^{*}$ \\
\hline Sperm count (million /ml) & $-0.947 *$ & $<0.001 *$ \\
\hline $\begin{array}{l}\text { Sperm motility (active } \\
\text { progressive } \% \text { first hour) }\end{array}$ & $-0.841 *$ & $<0.001^{*}$ \\
\hline Sperm morphology (abnormal forms \%) & $0.921 *$ & $<0.001^{*}$ \\
\hline $\begin{array}{l}\text { r: Pearson coefficient } \\
* \text { : Statistically significant at } p \leq 0.05\end{array}$ & & \\
\hline
\end{tabular}




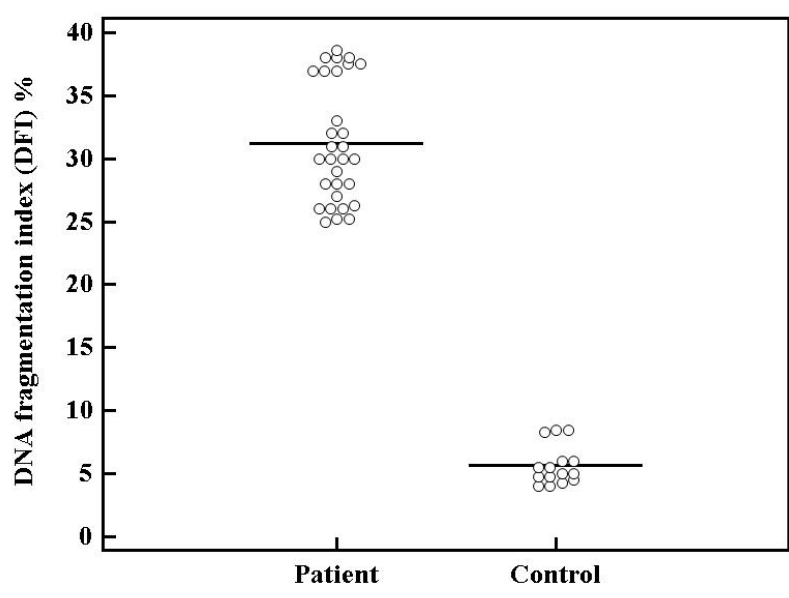

Fig. 1: Comparison between the studied groups according to DNA fragmentation index (DFI) \%.

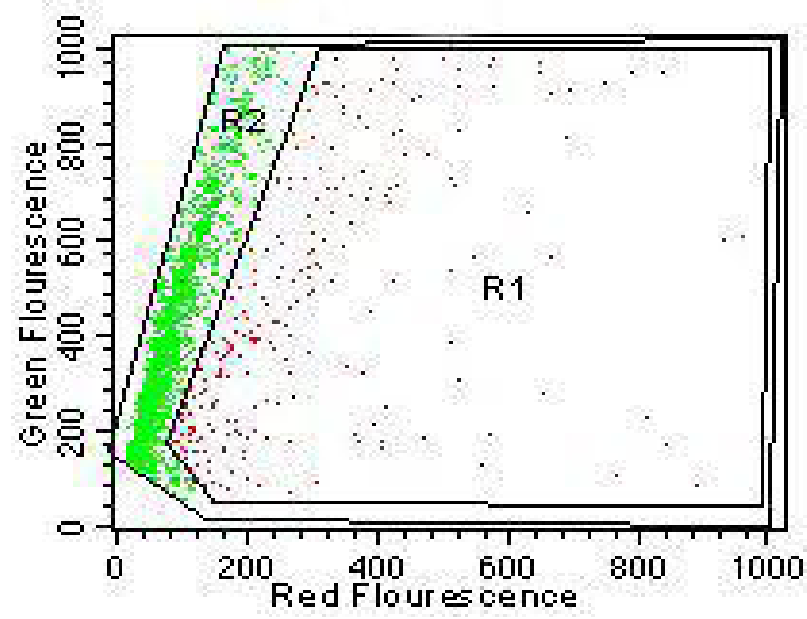

Fig. 2: Cytogram of one of the controls, R1: Number of sperms with fragmented DNA (red fluorescence). R2: Number of sperms with fragmented DNA (red fluorescence) + number of sperms with intact DNA (green fluorescence). DNA fragmentation index $(\mathrm{DFI})=\mathrm{R} 1 / \mathrm{R} 2 \%, \mathrm{DFI}=8 \%$.

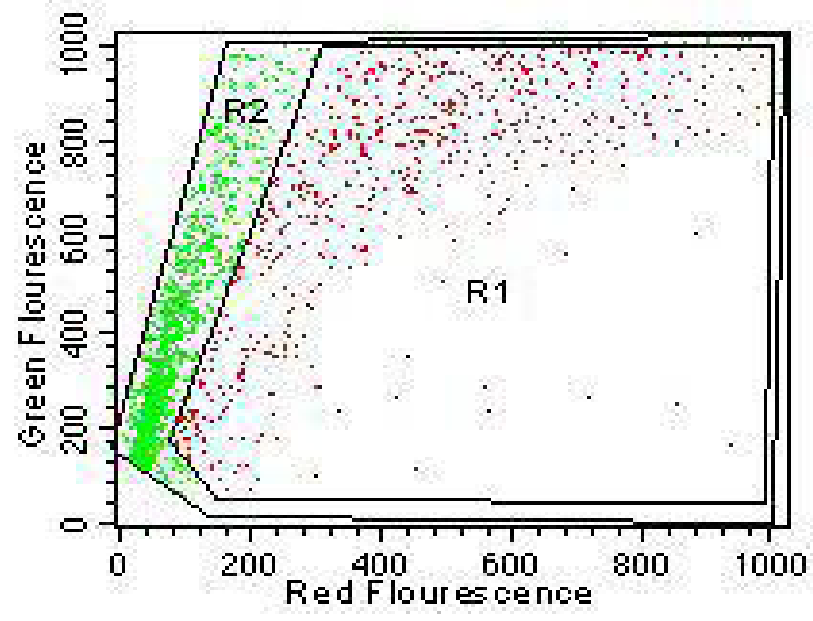

Fig. 3: Cytogram of 33 years old smoker with $\mathrm{SI}=520$ (heavy smoker), DFI $=37 \%$.

\section{DISCUSSION}

The relationship between genomic integrity and male fertility has been the subject of intense research over the past decade. Numerous reports have demonstrated an increase in sperm DNA damage in infertile men. Furthermore, sperm DNA integrity has been shown to be predictive of the time taken to achieve a pregnancy. However, damage to sperm DNA does not necessarily affect fertilization ${ }^{[10,14]}$.

The aetiology of sperm DNA damage is multifactorial, including deficient chromatin packing, abortive apoptosis, environmental pollutants and protamine deficiency. Moreover, increased oxidative stress is recognized as one of the main aetiological factors. Sperm are particularly susceptible to damage by excessive levels of ROS, due to their high content of unsaturated fatty acids and relative lack of cytosolic antioxidant protection. The absence of DNA repair mechanisms further exacerbates this effect ${ }^{[15]}$.

Although DNA repair does occur in developing spermatozoa, this ceases late in spermatogenesis. As a result, ejaculated sperm have no mechanism to repair DNA damage during their transit and storage in the epididymis. Since this damage does not influence fertilization or even the first few stages of embryo cleavage, spermatozoa with damaged DNA still have the potential to reach the oocyte, achieve fertilization leading to a potentially viable embryo. The oocyte has only a limited ability to repair damaged sperm DNA. If such damage is inadequately repaired, it may predispose to increased rates of embryonic failure, pregnancy loss, mutations and thus inherited diseases in the offspring. Indeed, germ cell mutations are recognized to occur much more frequently in the paternal, rather than maternal, germ line, a fact that contributes significantly to the occurrence of inherited diseases $^{[16,17]}$.

It has been emphasized that human spermatozoa are particularly susceptible to oxidative stress-induced damage by ROS because their plasma membranes are rich in polyunsaturated fatty acids. The ROS in tobacco smoking induce lipid peroxidation of the sperm plasma membrane; this is considered to be the key mechanism in inducing sperm damage that leads to decreased sperm viability, sperm concentration, sperm motility, and increased morphological defects ${ }^{[18]}$.

This study was carried out on 30 infertile, smoker, male patients in a trial to assess sperm DNA damage in these patients. Sperm DNA damage was assessed using SCSA by flow cytometer.

In the present study, semen analysis of the studied patients showed that $24(80 \%)$ patients 
had asthenozoospermia and there was statistically significant decrease in sperm motility in patients compared to control. There was no statistically significant difference in mean value of sperm count in patients compared to the controls. On the other hand, there was a statistically significant increase in the sperm abnormal forms in patients compared to controls, and there was statistically significant decreased in semen volume in the patients when compared to control.

The present study showed statistically significant reduction in sperm count and sperm motility in cigarette smokers as compared to non-smokers that was in accordance with a study done by Künzle et $a l \cdot{ }^{[19]}$ who evaluated many men attending a fertility clinic; found that cigarette smoking was associated with reductions in sperm concentration, motility and normal morphology as in the present study. Also in a study done by Mehrania in $\operatorname{Iran}^{[20] \text {; }}$ decreased sperm concentration was observed in the heavy smokers compared to the non-smokers that were in accordance with the present study. However, Hessa et $a l .{ }^{[20]}$ found no correlation between smoking and changes in sperm concentration.

This study showed that the frequency of abnormal morphology increased as the number of tobacco sticks smoked per day increased; putting smokers at a higher risk of developing teratozoospermia. The present study was in agreement with Elshal, et al. ${ }^{[21]}$ who reported that cigarette smoking increases the percentage of morphologically altered spermatozoa. This might be as a result of the presence of toxic chemicals, mutagenic and carcinogenic compounds found in cigarette smoke, which adversely affect sperm morphology.

The current study showed a statistically significant increase in DNA fragmentation index (DFI) in patients compared to controls. This was accordance with that reported by Sepaniak et al who found the spermatozoa of smokers have a significantly higher DNA fragmentation than those of non-smokers. They also found some trend toward lower sperm motility in spermatozoa with DNA fragmentation $>35 \%{ }^{[22]}$.

In this study, DFI ranged from $25-38 \%$ in the patients and all were infertile, while DFI is ranged from $4-10 \%$ in the controls. Evenson et al. ${ }^{[23]}$ revealed that if DFI was $>27 \%$, the oocyte DNA repair capacity was exceeded, resulting in progressive loss of chromosomally abnormal embryos, with repeated spontaneous abortion and even longer time to achieve pregnancy. Even with ARTs, the ability to achieve pregnancy by IUI is decreased significantly if DFI is above $30 \%$. ICSI treatment is more likely to result in pregnancy than IVF in such cases. However, increased incidence of congenital malformation among children born after ICSI and increased incidence of childhood cancer is well known.

In the current study, $4(13 \%)$ of patients who were heavy smokers, their DFI ranged from $27-33 \%$, their wives were complaining of recurrent abortion at the first trimester that reached in some cases to nine times and most of them were twins. This might have strong evidence that smokers can be fertile but they may suffer from several problems in achieving pregnancy and even congenital malformation can occur.

In the present study, it was demonstrated that sperm DFI is positively correlated with age. These finding were in agreement with previous studies showing that advancing paternal age is linked to sperm chromatin defects. Moskovtsev et al. ${ }^{[24]}$ reported that DFI was significantly higher in men more than 45 years old, with \% DFI doubling in those men 45 years and older compared to those less than 30 years old. Singh et al. (25) reported that the percentage of sperm with highly damaged DNA was significantly higher in men aged 36-57 years than in those aged 20-35 years which was supporting to the current results.

The present study showed significant negative correlation between DFI and sperm motility that was in agreement with the study done by Roessner et al..$^{[26]}$. These findings also corresponded well with another report by La Vignera et al. ${ }^{[27]}$. A significant positive correlation was found between DFI and sperm morphology (abnormal forms \%), significant negative correlation could be detected between the DFI and other seminal parameters including: semen volume $(\mathrm{ml})$ and sperm count $($ millions $/ \mathrm{ml})$ in the current study this meaned that when DFI increased, there is increase in the abnormal forms and a decrease in the count, motility and volume. A significant positive correlations between DFI and both SI and the duration of smoking were observed in the current study. So DFI\% increased when there were higher SI and longer duration.

In this study, there was a negative correlation between SI and semen volume $(\mathrm{ml})$, sperm count (millions $/ \mathrm{ml}$ ) and motility (active progressive \%, first hour).On the other hand there was a positive correlation between SI and sperm morphology (abnormal forms), so heavy smokers have a lowest semen volume, sperm count and motility with increasing the abnormal forms in contrast to mild and moderate smokers and the controls. These findings matched with studies done by Wang et al. ${ }^{[28]}$, Mostafa ${ }^{[29]}$ et al Harlev et al..$^{[30]}$. There was also negative correlation between the duration of smoking and semen volume, sperm counts and motility while a positive correlation between the duration of smoking and sperm morphology (abnormal forms\%) was found. 
In sperms, cigarette smoke increases ROS production while decreasing antioxidant capacity leading to DNA damage. The extent of this damage depends of many factors as duration of smoking and SI. Thus accumulation of damaged DNA and loss of DNA integrity has been documented to be the underlying cause of idiopathic cases of infertility, recurrent abortions, congenital malformations and even childhood cancer by induction of genetic and epigenetic changes in the sperm DNA.

\section{CONCLUSION}

The current study showed an increase in DFI in smokers when compared to controls. There was a positive correlation between DFI and both SI and duration of smoking. Sperm DNA damage also affect the quality of the ejaculated spermatozoa and may have an impact on their fertility potential. Sperm DNA damage may be a possible etiological factor of smoking associated infertility, repeated abortion, inherited diseases or even increased incidence of cancer in the offspring of these smokers. Further studies on a large number of smokers are needed to clarify the significance of sperm DNA damage in smoking related infertility and to determine the possible underlying mechanisms.

\section{CONFLICT OF INTEREST}

There are no conflicts of interest.

\section{REFERENCES}

1. Rubes J, Selevan SG, Evenson DP, et al: Episodic air pollution is associated with increased DNA fragmentation in human sperm without other changes in semen quality. Hum Reprod 2005; 20(10):2776 -86.

2. Zenzes MT: Smoking and reproduction: gene damage to human gametes and embryos. Hum Reprod 2000; 6(2):122-31

3. Zinaman MJ, Brown CC, Selevan SG, Clegg ED: Semen quality and human fertility: a prospective study with healthy couples. J Androl 2000; 21(1):145-153.

4. Colagar AH, Jorsaraee GA, Marzony ET: Cigarette smoking and the risk of male infertility. Pak J Biol Sci 2007; 10(21): 3870-3874.

5. Reina Bouvet B, Vicenta Paparella C, Nestor Feldman R: Effect of tobacco consumption on the spermatogenesis in males with idiopathic infertility. Arch Esp Urol 2007; 60(3): 2737-.

6. Agarwal A, Virk G, Ong C, Stefaan S: Effect of Oxidative Stress on Male Reproduction. World J Mens Health 2014; 32(1): 1-17.
7. Niu ZH, Liu JB, Shi TY, Yuan Y, Shi HJ: Impact of cigarette smoking on human sperm DNA integrity. Zhonghua Nan Ke Xue 2010; 16(4):300-304

8. Evenson DP, Wixon R: Clinical aspects of sperm DNA fragmentation detection and male infertility. Theriogenology 2006; 65(5): 979 -991.

9. Moskovtsev SI: Management of patients with high sperm DNA damage. Indian J Med Res 2008; 127(2): $101-103$

10. Verhofstad N, Linschooten JO, Benthem JV, et al: New methods for assessing male germ line mutations in humans and genetic risks in their offspring. Mutagenesis 2008; 23(4):241 -7.

11. Nitti V, de Michele G, Famiglietti B, Miniccuci E, Ortolani G, SessaT, Lauro N: Epidemiological survey of chronic bronchitis in the city of Naples with special reference to the role and possible interaction of various exogenous factors. Bull Int Union Tuberc 1976; 51(1 Pt 2):685-99.

12. WHO Laboratory manual for the examination of human semen and semen-cervical mucus interaction. $4^{\text {th }}$ ed. Cambridge: Cambridge University Press; 1999. pp. 23-25.

13. Evenson D, Jost L. Sperm chromatin structure assay for fertility assessment. Curr Protoc Cytom 2001; $7: 1-27$.

14. O'Brien J, Zini A: Sperm DNA integrity and male infertility. Urology 2005; 65(1): 16-22.

15. Aitken RJ, Baker MA, Sawyer D: Oxidative stress in the male germ line and its role in the aetiology of male infertility and genetic disease. Reprod Biomed Online 2003; 7(1):65-70.

16. Carrell DT, Liu L, Peterson CM, Jones KP, Hatasaka $\mathrm{HH}$, Erickson L, Campbell B: Sperm DNA fragmentation is increased in couples with unexplained recurrent pregnancy loss. Arch Androl 2003; 49(1): 49-55.

17. Ji BT, Shu XO, Linet MS, et al: Paternal cigarette smoking and the risk of childhood cancer among offspring of nonsmoking mothers. J Natl Cancer Inst 1997; 89:238-244.

18. Hussein A, Al Gadaa A, El Faras M, El Fiky M: Effect of Tobacco Smoking on Semen Quality in Men With Subfertility. Urotoday Internat J 2011; 4(1): 717- 719.

19. Kunzle R, Mueller MD, Hanggi W, Birkhauser MH, Drescher H, Bersinger NA: Semen quality of male 
smokers and non-smokers in infertile couples. Fertil, Steril 2003; 79(2):287- 291.

20. Hessa H, Yildirim A, Can C, Turgut M, Tanir HM, Senses T, Sahin-Mutlu F: Effect of smoking on semen parameters of men attending an infertility clinic. Clin Exp obstet Gynecol 2006; 33(1):19-22.

21. Elshal MF, El-Sayed IH, Elsaied MA, El-Masry SA, Kumosani TA: Sperm head defects and disturbances in spermatozoal chromatin and DNA integrities in idiopathic infertile subjects: association with cigarette smoking. Clin Biochem 2009; $42(7$-8): 589 -94.

22. Sepaniak S, Forges T, Monnier-Barbarino P: Cigarette smoking and fertility in women and men. Gynecol Obstet Fertil 2006; 34(10), 945- 949.

23. Evenson DP, Wixon R: Clinical aspects of sperm DNA fragmentation detection and male infertility. Theriogenology 2006; 65(5): 979- 991.

24. Moskovtsev SI, Willis J, Mullen JB: Age-related decline in sperm deoxyribonucleic acid integrity in patients evaluated for male infertility. Fertil Steril 2006; 85(2):496-499.
25. Singh NP, Muller CH, Berger RE: Effects of age on DNA doubles strand breaks and apoptosis in human sperm. Fertil Steril 2003; 80(6):1420-30.

26. Roessner C, Paasch U, Kratzsch J, Glander HJ, Grunewald S: Sperm apoptosis signaling in diabetic men. Rep Biomed Online 2012; 25(3): 292 -299.

27. La Vignera S, Condorelli RA, Vicari E, D'Agata R, Salemi M, Calogero AE: High levels of lipid peroxidation in semen of diabetic patients. Andrologia 2012; 44(1): 565-570.

28. Wang SL, Wang XR, Chia SE, Shen HM, Somng L, Xing HX, et al: study on occupational exposure to petrochemicals and smoking on seminal quality. J Androl 2001; 22 (1):73 - 8.

29. Mostafa T: Smoking and male infertility. J Advanced Androl 2010; 1:179-186.

30. Harlev A, Agarwal A, Gunes SO, Shetty A, du Plessis SS. Smoking and Male Infertility: An Evidence-Based Review. World J Mens Health. 2015; 33(3):143 -60. 